\title{
Desempenho de frangos de corte alimentados com ingrediente de alta digestibilidade nas fases de criação pré-inicial e inicial
}

Henrique Müller Dallmann(1), Valdir Silveira de Avila(2), Paulo Antonio Rabenschlag de Brum², Paulo Tabajara Chaves Costa ${ }^{(3)}$, Arlei Coldebella (2), Paulo Roberto Dallmann(4), João Carlos Maier(1) e Fernando Rutz ${ }^{(1)}$

(1)Universidade Federal de Pelotas (UFPel), Departamento de Zootecnia, Avenida Eliseu Maciel, s/no, Campus Universitário, CEP 96010-900 Pelotas, RS. E-mail: henriquedallmann@yahoo.com.br, jcmaier@ufpel.edu.br, frutz@alltech.com. (2)Embrapa Suínos e Aves, BR 153, Km 110, Caixa Postal 21, CEP 89700-000 Concórdia, SC. E-mail: vavila@cnpsa.embrapa.br, pbrum@cnpsa.embrapa.br, arlei@cnpsa.embrapa.br ${ }^{(3)}$ Vitagri Indústria, Comércio e Serviços Ltda., Avenida Minas Gerais, no 2.614, CEP 86812-490 Apucarana, PR. E-mail: taba@vitagri.com.br (4)UFPel, Conjunto Agrotécnico Visconde da Graça, Avenida Ildefonso Simões Lopes, no 2791, CEP $96060-290$ Pelotas, RS. E-mail: prdallmann@yahoo.com.br

Resumo - O objetivo deste trabalho foi avaliar o efeito de dieta, com inclusão de um núcleo energético-proteico (NEP) de alta digestibilidade, no desempenho produtivo e características de carcaça de frangos de corte. O NEP constituiu-se de composto de óleo degomado de soja, milho pré-gelatinizado, soja biprocessada, mananoligossacarídeos e peptídeos. O total de 864 pintainhos machos, da linhagem AgRoss 508, com um dia de idade, foram pesados individualmente e distribuídos em blocos ao acaso. Os tratamentos consistiram de suplementos com diferentes teores de NEP, com oito repetições com 27 aves cada: T1, controle, $0 \%$ de NEP; T2, 7\% de NEP (1-7 dias) e 3,5\% de NEP (8-21 dias); T3, 14\% de NEP (1-7 dias) e 7\% de NEP (8-21 dias); e T4, 21\% de NEP (1-7 dias) e 10,5\% de NEP (8-21 dias). Aos 21 dias de idade, o peso corporal, ganho de peso, consumo médio de ração, conversão alimentar e rendimento de carcaça e cortes não foram afetados significativamente pelos tratamentos experimentais. A utilização de NEP na dieta de frangos de corte não altera o desempenho das aves e não interfere nas variáveis de características de carcaça.

Termos para indexação: mananoligossacarídeos, milho pré-gelatinizado, óleo degomado de soja, peptídeos, soja biprocessada.

\section{Performance of broilers fed with highly digestible ingredient in the prestarter and starter raising periods}

\begin{abstract}
The objective of this work was to evaluate the effect of the diet, with the inclusion of an energetic-protein nucleus (EPN) composed of highly digestible ingredients, on the productive performance and carcass traits of broiler chicks. The nucleus was composed by degummed soybean oil, pre-gelatinized corn, twice-processed soybean, mannanoligosaccharides and peptides. The total of 864 male AgRoss 508 broiler, with one day of age, were weighed individually and distributed in a randomized block design. Treatments consisted of: T1, control, $0 \%$ EPN; T2, 7\% EPN (1-7 days) and 3.5\% EPN (8-21 days); T3, 14\% EPN (1-7 days) and 7\% EPN (8-21 days); and T4, 21\% EPN (1-7 days) and 10.5\% EPN (8-21 days of age). At 21 days of age, body weight, weight gain, average feed intake, feed conversion and carcass and cut-ups yield were not significantly affected by treatments. The EPN inclusion in the diets did not influence the performance, carcass traits and cut-ups of broilers.
\end{abstract}

Index terms: mannanoligosaccharides, pre-gelatinized corn, degummed soybean oil, peptides, twice-processed soybean.

\section{Introdução}

Para melhor desempenho de frangos de corte recomenda-se uma dieta diferenciada, constituída por ingredientes de alta qualidade, nos primeiros dias de vida das aves, porque neste período, principalmente na primeira semana, o sistema enzimático da ave é pouco desenvolvido (Oliveira et al., 2009). Na fase pré-inicial do frango de corte (1-7dias), o consumo de ração é baixo em comparação às demais fases, correspondendo a $3,5 \%$ do total. $\mathrm{O}$ baixo consumo justifica o uso de ingredientes de alta digestibilidade na formulação de dietas, para favorecer o aproveitamento de nutrientes, pois, nesta fase da vida, as aves não estão plenamente adaptadas à ingestão de carboidratos e lipídios (Oliveira et al., 2009). Alguns exemplos de ingredientes de alta digestibilidade, utilizados como substitutos nas dietas dos animais nas fases pré-inicial e inicial, são: o 
óleo degomado de soja, a soja biprocessada, o milho pré-gelatinizado, os mananoligossacarídeos e os peptídeos.

O óleo degomado de soja (ODS) é obtido por meio dos processos de extração e degomagem do óleo de soja cru. São poucas as informações referentes à composição e valor nutricional do ODS, mas sabese que, como solução alternativa, é utilizado em formulações de rações para frangos de corte, para redução de custo (Vieira et al., 2002). Os resultados de alguns trabalhos têm demonstrado que esses óleos são uma fonte aceitável de energia suplementar para frangos e são ricos em ácidos graxos poli-insaturados (Freitas et al., 2005).

A soja in natura contém algumas substâncias que inibem o aproveitamento das proteínas e dos demais nutrientes das dietas pelos não ruminantes. Os principais fatores antinutricionais são os que reduzem a ação da tripsina e da quimiotripsina e causam perda no desempenho desses animais. Ao contrário do que se acreditava, a soja crua possui também quantidade apreciável de polissacarídeos não amiláceos (PNA) na forma de pectinas, hemiceluloses e dos oligassacarídeos rafinose e estaquiose, que afetam o tempo de trânsito da digesta e a motilidade intestinal e são barreiras físicas à ação das enzimas digestivas (Oliveira et al., 2009). A eliminação desses componentes, que representam cerca de 4 a $6 \%$ do conteúdo nutricional da soja, e a manutenção da qualidade nutricional podem ser feitas por processamento térmico, uma vez que esses componentes são inativados por altas temperaturas. $\mathrm{O}$ processamento melhora a aceitabilidade da soja, em razão da formação de substâncias resultantes da condensação de glicídios e aminoácidos (Perilla et al., 1997).

O milho pré-cozido ou gelatinizado é o produto obtido pelo processamento dos grãos inteiros sadios de milho (Zea mays L.), pelo calor e pressão a vácuo, a partir de grãos degerminados, moídos e submetidos às operações de pré-gelatinização por extrusão, que são posteriormente secos, moídos e classificados. Esse processo também melhora a digestibilidade dos lipídeos presentes nos grãos, pelo rompimento das estruturas celulares que os protegem (Stringhini et al., 2009).

Os prebióticos são uma alternativa natural para a utilização de promotores de crescimento na dieta animal, e os oligossacarídeos estão entre os mais pesquisados. Dentro desse grupo podem ser citados os mananoligossacarídeos (MOS), que são derivados da parede celular da levedura Saccharomyces cerevisiae. Os benefícios dos MOS baseiam-se nas propriedades específicas, que incluem a modificação da flora intestinal, a redução da taxa de renovação da mucosa intestinal ("turnover") e a estimulação do sistema imune (Hofacre et al., 2003).

Os aminoácidos e os oligopeptídeos são absorvidos no trato gastrintestinal, o que completa as necessidades dos animais para atender ao crescimento e à manutenção. Alguns fatores podem explicar este fato: aminoácidos livres são bem absorvidos no intestino delgado proximal e os di- e tripeptídeos são absorvidos em todo o intestino delgado 10 vezes mais rapidamente do que os aminoácidos livres; alguns aminoácidos livres competem pelo mesmo carreador, o que faz com que haja inibição da absorção; os di- e tripeptídeos apresentam maior absorção do que os tetrapeptídeos, com moléculas maiores, visto que estes precisam ser hidrolisados primeiramente, a fim de serem absorvidos (Macari \& Maiorka, 2000).

Assim, a utilização de ingredientes de alta digestibilidade, na formulação de dietas, se justifica, uma vez que favorecerão o aproveitamento de nutrientes.

O objetivo deste trabalho foi avaliar o efeito de dieta com inclusão de um núcleo energético-proteico (NEP) de alta digestibilidade, constituído por óleo degomado de soja, soja biprocessada, milho pré-gelatinizado, mananoligossacarídeos e peptídeos, no desempenho produtivo e características de carcaça de frangos de corte até 21 dias de idade.

\section{Material e Métodos}

O experimento foi conduzido nas instalações do Campo Experimental do Suruvi, da Embrapa Suínos e Aves, no Município de Concórdia, SC, de 10 de novembro a 22 de dezembro de 2008, no total de 42 dias.

Foram alojados 864 pintainhos machos de corte, da linhagem AgRoss 508, com um dia de idade, em 32 boxes de 1,50x1,80 m cada. Os boxes previamente preparados continham um círculo de proteção, campânula com lâmpada para o aquecimento, cama de maravalha de 10-12 $\mathrm{cm}$ de altura e bandejas para ração inicial e bebedouros infantis. Ao final dos três 
primeiros dias, as bandejas foram substituídas por comedouros tubulares, e o fornecimento de água foi substituído por bebedouros pendulares. Os círculos de proteção de cada boxe foram retirados aos 10 dias, e o sistema de aquecimento (campânula) aos 21 dias. A temperatura foi controlada de acordo com a idade dos animais.

Os animais foram pesados individualmente, distribuídos em blocos e, em seguida, alojados nos boxes com 27 aves cada, que constituíram as unidades experimentais. O peso dos animais variou de 41 a $52 \mathrm{~g}$, e o peso médio de cada tratamento foi de $46 \mathrm{~g}$. Dividiram-se os animais em quatro tratamentos, com oito repetições com 27 aves cada. Os tratamentos consistiram das dietas suplementadas com diferentes teores de um núcleo energético-proteico (NEP), constituído por um concentrado nutritivo composto de soja biprocessada, peptídeos, mananoligossacarídeos, milho pré-gelatinizado e óleo degomado de soja. Os tratamentos foram ministrados até o $21^{\circ}$ dia de vida dos frangos e, a partir dessa data até o final do experimento aos 42 dias, todos os animais receberam uma dieta basal única. As dietas eram isoproteicas e isoenergéticas entre si e formuladas para atingir as exigências nutricionais da espécie, conforme Rostagno et al. (2005). Utilizaram-se ingredientes para alcançar as necessidades nas fases pré-inicial, inicial (Tabela 1), crescimento e final (Tabela 2). Os teores nutricionais foram calculados para a composição das dietas pré-iniciais, iniciais (Tabela 3), crescimento e final (Tabela 4).

As aves foram pesadas coletivamente, por boxe, em balança eletrônica com precisão de $5 \mathrm{~g}$, nos dias $1,7,21,35$ e 42, para determinação das variáveis de desempenho como peso corporal e ganho de peso. Foi realizado, ainda, o controle do fornecimento de ração aos animais, para o cálculo do consumo médio de ração e conversão alimentar.

Aos 42 dias, todas as aves foram pesadas, e tendose definido o peso médio de mais ou menos $40 \mathrm{~g}$ em cada unidade experimental, duas delas foram anilhadas e levadas ao Abatedouro Experimental da Embrapa Suínos e Aves, para avaliação do rendimento de carcaça e cortes. As aves foram pesadas novamente e identificadas no momento da apanha para o abate. As carcaças sem sangue e depenadas foram evisceradas

Tabela 1. Composição percentual das dietas nas fases pré-inicial e inicial, em diferentes tratamentos de inclusão de núcleo energético-proteico (NEP) nas dietas ${ }^{(1)}$.

\begin{tabular}{|c|c|c|c|c|c|c|c|c|}
\hline \multirow[t]{2}{*}{ Matérias Primas } & \multicolumn{4}{|c|}{ Dietas pré-iniciais } & \multicolumn{4}{|c|}{ Dietas iniciais } \\
\hline & $\mathrm{T} 1$ & $\mathrm{~T} 2$ & T3 & $\mathrm{T} 4$ & $\mathrm{~T} 1$ & $\mathrm{~T} 2$ & T3 & $\mathrm{T} 4$ \\
\hline Milho & 55,046 & 53,191 & 50,099 & 47,495 & 60,003 & 59,500 & 58,998 & 58,495 \\
\hline Farelo de soja & 37,112 & 33,149 & 29,457 & 25,382 & 32,841 & 30,149 & 27,457 & 24,765 \\
\hline Óleo de soja & 2,755 & 1,880 & 1,665 & 1,351 & 2,495 & 2,180 & 1,865 & 1,551 \\
\hline Calcário & 1,335 & 1,247 & 1,250 & 1,252 & 1,235 & 1,237 & 1,240 & 1,242 \\
\hline Fosfato bicálcico & 1,984 & 1,790 & 1,787 & 1,784 & 1,794 & 1,790 & 1,787 & 1,784 \\
\hline Cloreto de sódio & 0,517 & 0,509 & 0,508 & 0,503 & 0,457 & 0,459 & 0,460 & 0,462 \\
\hline L-lisina & 0,154 & 0,160 & 0,166 & 0,172 & 0,124 & 0,130 & 0,136 & 0,142 \\
\hline DL-metionina & 0,235 & 0,216 & 0,212 & 0,206 & 0,209 & 0,209 & 0,208 & 0,208 \\
\hline L-treonina & 0,142 & 0,134 & 0,132 & 0,131 & 0,146 & 0,149 & 0,152 & 0,155 \\
\hline $\mathrm{BHT}^{(2)}$ & 0,015 & 0,015 & 0,015 & 0,015 & 0,015 & 0,015 & 0,015 & 0,015 \\
\hline Mastersorb $^{(3)}$ & 0,200 & 0,200 & 0,200 & 0,200 & 0,200 & 0,200 & 0,200 & 0,200 \\
\hline Cloreto de colina & 0,334 & 0,334 & 0,334 & 0,334 & 0,307 & 0,307 & 0,307 & 0,307 \\
\hline Rovimix Aves ${ }^{(4)}$ & 0,100 & 0,100 & 0,100 & 0,100 & 0,100 & 0,100 & 0,100 & 0,100 \\
\hline Roligomix Aves $^{(5)}$ & 0,050 & 0,050 & 0,050 & 0,050 & 0,050 & 0,050 & 0,050 & 0,050 \\
\hline Monensina & 0,025 & 0,025 & 0,025 & 0,025 & 0,025 & 0,025 & 0,025 & 0,025 \\
\hline $\operatorname{NEP}(\%)^{(6)}$ & 0,000 & 7,000 & 14,000 & 21,000 & 0,000 & 3,500 & 7,000 & 10,500 \\
\hline Total & 100,00 & 100,00 & 100,00 & 100,00 & 100,00 & 100,00 & 100,00 & 100,00 \\
\hline
\end{tabular}

${ }^{(1)}$ Teor de inclusão de NEP nas dietas: T1, 0\% em todo o período (42 dias); T2, 7\% até 7 dias de idade e 3,5\% até 21 dias; T3, 14\% até 7 dias e 7\% até 21 dias; T4, 21\% até 7 dias e 10,5\% até 21 dias. ${ }^{(2)}$ Butil-hidroxitolueno. ${ }^{(3)}$ Aluminossilicatos de sódio + cálcio hidratado. ${ }^{(4)}$ Níveis de garantia por quilograma do produto: vitamina A, 12.000.000 UI; vitamina D3, 2.500.000 UI; vitamina E, 30.000 UI; vitamina B1, 2 g; vitamina B6, 3 g; pantotenato de cálcio, $10 \mathrm{~g}$; biotina, $0,07 \mathrm{~g}$; vitamina K3, $3 \mathrm{~g}$; ácido fólico, $1 \mathrm{~g}$; ácido nicotínico, $35 \mathrm{~g}$; bacitracina de zinco, $10 \mathrm{~g}$; cloreto de colina, $100 \mathrm{~g}$; vitamina B12, 15.000 mcg; selênio, 0,12 g; ${ }^{(5)}$ Níveis de garantia por quilograma do produto: manganês, 160 g; ferro, 100 g; zinco, 100 g; cobre, 20 g; cobalto, 2 g; iodo, 2 g. ${ }^{(6)}$ Núcleo energético-proteico composto de óleo degomado de soja; soja biprocessada; milho pré-gelatinizado; mananoligossacarídeos e peptídeos. 
manualmente, para obtenção do peso da carcaça, eviscerada com patas e com cabeça. Para o rendimento de carcaça, foi considerada a diferença entre o peso da carcaça eviscerada e o peso vivo no momento da apanha. Para as características de carcaça, foram separados e pesados: coxas, sobrecoxas, asas, peito e gordura abdominal.

A análise dos dados de desempenho foi realizada por meio da teoria de modelos mistos para medidas repetidas, tendo-se considerado os efeitos de bloco, tratamento, idade das aves e a interação desses dois últimos fatores, e 16 tipos de estruturas de matrizes de variâncias e covariâncias, com uso do Proc Mixed do SAS, conforme Xavier (2000), em que a estrutura a ser usada na análise foi escolhida com base no menor valor do critério de informação de Akaike (AIC). O método de estimação usado foi o de máxima verossimilhança restrita. No caso das variáveis ligadas às características de carcaça, foi realizada a análise da variância pelo procedimento GLM do SAS, em que se considerou o modelo para o delineamento em blocos inteiramente ao acaso. A análise inicial, realizada por meio da macro de Xavier (2000), com base no menor valor do AIC, levou às escolhas das matrizes de variâncias e covariâncias.

Tabela 2. Composição percentual das dietas nas fases de crescimento e final.

\begin{tabular}{|c|c|c|}
\hline Matérias Primas & Dieta crescimento & Dieta final \\
\hline Milho & 62,044 & 65,750 \\
\hline Farelo de soja & 30,307 & 26,340 \\
\hline Óleo de soja & 3,262 & 3,775 \\
\hline Calcário & 1,171 & 1,112 \\
\hline Fosfato bicálcico & 1,699 & 1,611 \\
\hline Sal comum & 0,407 & 0,357 \\
\hline L-lisina & 0,079 & 0,080 \\
\hline DL-metionina & 0,214 & 0,211 \\
\hline L-treonina & 0,158 & 0,131 \\
\hline $\mathrm{BHT}^{(1)}$ & 0,015 & 0,015 \\
\hline Mastersorb $^{(2)}$ & 0,200 & 0,200 \\
\hline Cloreto de colina & 0,269 & 0,269 \\
\hline Rovimix Aves OVN ${ }^{(3)}$ & 0,100 & 0,100 \\
\hline Roligomix Aves ${ }^{(4)}$ & 0,050 & 0,050 \\
\hline Monensina & 0,025 & 0,000 \\
\hline Total & 100,000 & 100,000 \\
\hline \multicolumn{3}{|c|}{$\begin{array}{l}{ }^{(1)} \text { Butil-hidroxitolueno. }{ }^{(2)} \text { Aluminossilicatos de sódio }+ \text { cálcio hidratado. } \\
\text { (3) Níveis de garantia por quilograma do produto: vitamina A, } 12.000 .000 \\
\text { UI; vitamina D3, } 2.500 .000 \mathrm{UI} \text {; vitamina E, } 30.000 \mathrm{UI} \text {; vitamina B1, } \\
\mathrm{g} \text {; vitamina B6, } 3 \mathrm{~g} \text {; pantotenato de cálcio, } 10 \mathrm{~g} \text {; biotina, } 0,07 \mathrm{~g} \text {; vitamina } \\
\mathrm{K} 3,3 \mathrm{~g} \text {; ácido fólico, } 1 \mathrm{~g} \text {; ácido nicotínico, } 35 \mathrm{~g} \text {; bacitracina de zinco, } \\
10 \mathrm{~g} \text {; cloreto de colina, } 100 \mathrm{~g} \text {; vitamina B12, } 15.000 \mathrm{mcg} \text {; selênio, } 0,12 \mathrm{~g} \text {; } \\
\text { (4)Níveis de garantia por quilograma do produto: manganês, } 160 \mathrm{~g} \text {; ferro, } \\
100 \mathrm{~g} \text {; zinco, } 100 \mathrm{~g} \text {; cobre, } 20 \mathrm{~g} \text {; cobalto, } 2 \mathrm{~g} \text {; iodo, } 2 \mathrm{~g} \text {. }\end{array}$} \\
\hline
\end{tabular}

\section{Resultados e Discussão}

O peso corporal das aves em todos os períodos avaliados não apresentou diferença significativa entre os tratamentos, o que indica que a adição do núcleo energético-proteico (NEP) à dieta dos frangos não influenciou essa variável (Tabela 5). Isso nos leva a acreditar que a dieta basal já continha todos os nutrientes necessários para maximizar o desempenho desses animais. Waldroup et al. (2003), que utilizaram mananoligossacarídeos (MOS), concluíram também que sua adição à dieta de frangos não causou efeito no peso corporal das aves. Entretanto, Rostagno et al. (2003) relataram que houve melhor desempenho dessa variável, em frangos de corte, ao avaliar a utilização de MOS na dieta.

A utilização do NEP não afetou o ganho de peso das aves (Tabela 5). Vários autores, que trabalharam com alguns constituintes do NEP utilizados no presente trabalho, também não observaram efeito dos suplementos - óleo degomado de soja (ODS) (Vieira et al., 2002), milho pré-gelatinizado (Freitas et al., 2003; Santos, 2006; Stringhini et al., 2009) e MOS (Hofacre et al., 2003) - no ganho de peso de frangos de corte.

Lara et al. (2005), trabalharam com ODS na dieta de frangos de corte e encontraram maior ganho de peso das aves, em comparação com as alimentadas com óleo ácido de soja; a explicação para isto foi que a maior concentração de triglicerídeos no ODS resulta em adequada relação de monoglicerídeos/ácidos graxos livres, o que facilita sua absorção e aproveitamento pela ave.

Santin et al. (2000) observaram diferenças significativas no ganho de peso de frangos de corte e encontraram aumento no tamanho de vilo da mucosa intestinal das aves suplementadas com prebiótico (MOS). Macari \& Maiorka (2000) também relataram melhoria no ganho de peso e maior altura dos vilos intestinais de frangos suplementados com peptídeos. Segundo Adibi \& Morse (1977), a utilização de aminoácidos, na forma de peptídeos, em razão de sua maior biodisponibilidade, é capaz de melhorar a condição do epitélio intestinal, e, assim, melhorar a absorção dos nutrientes.

A utilização do NEP também não influenciou o consumo de ração, pois não houve diferença significativa entre os tratamentos (Tabela 5). Esses 
resultados corroboram os de Brito (2005), que não constatou efeito significativo no consumo ao utilizar milho pré-gelatinizado nas rações. Duarte et al. (2010) utilizaram ODS e, também, não encontraram diferença estatisticamente significativa no consumo de ração de frangos de corte, mesmo quando o compararam a outras fontes lipídicas. Entretanto, Freitas et al. (2003) verificaram maior consumo de ração, quando usaram milho processado termicamente (pré-gelatinizado) na fase pré-inicial.

A conversão alimentar também não apresentou diferença significativa entre os tratamentos (Tabela 5). Resultados semelhantes foram obtidos por Faria (1994), que não verificou diferença na conversão alimentar entre grupos de frangos de corte tratados com soja tostada ou extrusada. Os dados do presente trabalho corroboram também os resultados obtidos por
Brito (2005), que não constatou efeito significativo na conversão alimentar ao utilizar milho pré-gelatinizado nas rações de frangos de corte.

No entanto, os resultados obtidos no presente trabalho não estão de acordo com os de Vieira et al. (2002), que avaliaram a inclusão de ODS e observaram melhor conversão alimentar dos animais suplementados; Sakomura et al. (2004), também mostraram que aves alimentadas com soja processada, tiveram melhor conversão alimentar. Hofacre et al. (2003) e Rostagno et al. (2003), em experimentos com frangos de corte, observaram melhoria significativa da conversão alimentar de animais alimentados com MOS.

No entanto, Freitas et al. (2003) e Santos (2006) verificaram que a utilização de milho pré-gelatinizado influenciou negativamente a conversão alimentar. Isso se justifica pela formação de beta-amilase e

Tabela 3. Níveis nutricionais calculados na composição das dietas pré-iniciais e iniciais, em diferentes tratamentos de inclusão de núcleo energético-proteico (NEP) nas dietas ${ }^{(1)}$.

\begin{tabular}{|c|c|c|c|c|c|c|c|c|}
\hline \multirow[t]{2}{*}{ Teores calculados } & \multicolumn{4}{|c|}{ Dietas pré-iniciais } & \multicolumn{4}{|c|}{ Dietas iniciais } \\
\hline & $\mathrm{T} 1$ & $\mathrm{~T} 2$ & T3 & $\mathrm{T} 4$ & $\mathrm{~T} 1$ & $\mathrm{~T} 2$ & T3 & $\mathrm{T} 4$ \\
\hline Proteína bruta (\%) & 21,000 & 21,000 & 21,000 & 21,000 & 19,500 & 19,500 & 19,500 & 19,500 \\
\hline Energia metabolizável (kcal) & 3.000 & 3.000 & 3.000 & 3.000 & 3.050 & 3.050 & 30.500 & 3.050 \\
\hline Cálcio (\%) & 0,990 & 0,990 & 0,990 & 0,990 & 0,950 & 0,950 & 0,950 & 0,950 \\
\hline Fósforo total (\%) & 0,680 & 0,680 & 0,680 & 0,680 & 0,640 & 0,640 & 0,640 & 0,640 \\
\hline Fósforo disponível (\%) & 0,470 & 0,470 & 0,470 & 0,470 & 0,430 & 0,430 & 0,430 & 0,430 \\
\hline Metionina $(\%)$ & 0,519 & 0,516 & 0,514 & 0,511 & 0,519 & 0,516 & 0,514 & 0,511 \\
\hline Metionina+cistina $(\%)$ & 0,840 & 0,840 & 0,840 & 0,840 & 0,840 & 0,840 & 0,840 & 0,840 \\
\hline Lisina $(\%)$ & 1,150 & 1,150 & 1,150 & 1,150 & 1,150 & 1,150 & 1,150 & 1,150 \\
\hline Fibra bruta $(\%)$ & 2,810 & 2,710 & 2,610 & 2,510 & 2,810 & 2,710 & 2,610 & 2,510 \\
\hline Colina $(\%)$ & 1,600 & 1,600 & 1,600 & 1,600 & 1,600 & 1,600 & 1,600 & 1,600 \\
\hline Tripsina $(\%)$ & 0,246 & 0,229 & 0,212 & 0,195 & 0,246 & 0,229 & 0,212 & 0,195 \\
\hline Treonina (\%) & 0,920 & 0,920 & 0,920 & 0,920 & 0,920 & 0,920 & 0,920 & 0,920 \\
\hline Arginina (\%) & 1,328 & 1,236 & 1,144 & 1,053 & 1,328 & 1,236 & 1,144 & 1,053 \\
\hline Isoleucina (\%) & 0,864 & 0,806 & 0,748 & 0,690 & 0,864 & 0,806 & 0,748 & 0,690 \\
\hline Valina (\%) & 0,949 & 0,889 & 0,829 & 0,769 & 0,949 & 0,889 & 0,829 & 0,769 \\
\hline Ácido linoleico (\%) & 2,660 & 2,470 & 2,270 & 2,070 & 2,660 & 2,470 & 2,270 & 2,070 \\
\hline Sódio (\%) & 0,220 & 0,220 & 0,220 & 0,200 & 0,200 & 0,200 & 0,200 & 0,200 \\
\hline Extrato etéreo (\%) & 5,200 & 5,070 & 4,940 & 4,810 & 5,200 & 5,070 & 4,940 & 4,810 \\
\hline Cloro (\%) & 0,300 & 0,300 & 0,300 & 0,300 & 0,300 & 0,300 & 0,300 & 0,300 \\
\hline Histidina $(\%)$ & 0,540 & 0,507 & 0,475 & 0,442 & 0,540 & 0,507 & 0,475 & 0,442 \\
\hline Lisina digestível (\%) & 1,180 & 1,105 & $1,, 050$ & 0,985 & 1,060 & 0,995 & 0,930 & 0,865 \\
\hline Metionina+cistina digestível (\%) & 0,770 & 0,738 & 0,706 & 0,674 & 0,770 & 0,738 & 0,706 & 0,674 \\
\hline Metionina digestível (\%) & 0,493 & 0,477 & 0,460 & 0,443 & 0,493 & 0,477 & 0,460 & 0,443 \\
\hline Arginina digestível (\%) & 1,267 & 1,179 & 1,091 & 1,003 & 1,267 & 1,179 & 1,091 & 1,003 \\
\hline Valina digestível (\%) & 0,844 & 0,790 & 0,736 & 0,683 & 0,844 & 0,790 & 0,736 & 0,683 \\
\hline Treonina digestível (\%) & 0,740 & 0,700 & 0,659 & 0,618 & 0,821 & 0,780 & 0,739 & 0,698 \\
\hline Triptofano digestível (\%) & 0,190 & 0,175 & 0,159 & 0,144 & 0,220 & 0,205 & 0,189 & 0,174 \\
\hline Isoleucina digestível (\%) & 0,787 & 0,734 & 0,681 & 0,628 & 0,787 & 0,734 & 0,681 & 0,628 \\
\hline
\end{tabular}

${ }^{(1)}$ Teor de inclusão de NEP nas dietas: T1, 0\% em todo o período (42 dias); T2, 7\% até 7 dias de idade e 3,5\% até 21 dias; T3, 14\% até 7 dias e 7\% até 21 dias; T4, $21 \%$ até 7 dias e $10,5 \%$ até 21 dias. 
amilopectina cristalizada, durante o processo de extrusão de carboidratos, que diminui a habilidade das enzimas amilases de romper as ligações do amido (Hongtrakul et al., 1998). O processo de extrusão dos carboidratos tem diferentes efeitos no desempenho, e o grau de gelatinização pode não ser o fator principal na explicação dessas variações.

Amortalidade média de frangos de corte, alimentados com suplementação de NEP, não apresentou diferença significativa, aos 42 dias de idade dos animais (Tabela 5). Fernandez \& Crespo (2003) também não verificaram efeito significativo na utilização de MOS na mortalidade. Os resultados do presente trabalho, no entanto, não estão de acordo com os valores obtidos por Swick (1996), que observou redução da mortalidade de animais alimentados com MOS, em experimento com frangos de corte.

Nenhuma das variáveis de desempenho, ligada às características de carcaça, foi afetada pelos tratamentos

Tabela 4. Níveis nutricionais calculados na composição das dietas de crescimento e final.

\begin{tabular}{lrc}
\hline Teores calculados & Dieta de crescimento & Dieta final \\
\hline Proteína bruta (\%) & 18,500 & 17,000 \\
Energia metabolizável (kcal) & $3.125,000$ & $3.200,000$ \\
Cálcio (\%) & 0,900 & 0,850 \\
Fósforo total (\%) & 0,620 & 0,590 \\
Fósforo disponível (\%) & 0,410 & 0,390 \\
Metionina (\%) & 0,511 & 0,489 \\
Metionina+cistina (\%) & 0,820 & 0,780 \\
Lisina (\%) & 1,050 & 0,950 \\
Fibra bruta (\%) & 2,710 & 2,560 \\
Colina (\%) & 1,400 & 1,400 \\
Triptofano (\%) & 0,231 & 0,209 \\
Treonina (\%) & 0,893 & 0,808 \\
Arginina (\%) $\%$ (\%) & 1,134 \\
Isoleucina (\%) & 1,251 & 0,744 \\
Valina (\%) & 0,816 & 0,832 \\
Ácido linoleico (\%) & 0,903 & 3,420 \\
Sódio (\%) & 3,100 & 0,160 \\
Extrato etéreo (\%) & 0,180 & 6,570 \\
Cloro (\%) & 5,990 & 0,250 \\
Histidina (\%) & 0,270 & 0,479 \\
Lisina digestível (\%) & 0,516 & 0,872 \\
Metionina+cistina digestível (\%) & 0,965 & 0,718 \\
Metionina digestível (\%) & 0,753 & 0,467 \\
Arginina digestível (\%) & 0,487 & 1,080 \\
Valina digestível (\%) & 1,193 & 0,739 \\
Treonina digestível (\%) & 0,802 & 0,720 \\
Triptofano digestível (\%) & 0,798 & 0,187 \\
Isoleucina digestível (\%) & 0,207 & 0,677 \\
\hline & 0,743 & \\
\hline
\end{tabular}

(Tabela 6), o que concorda com os estudos de Santos (2006), que não verificou efeito significativo da utilização de MOS sobre o rendimento de carcaça ou de cortes. Outros autores não observaram influência nas características de carcaça e cortes, devida às diferentes fontes lipídicas (Duarte et al., 2010), milho pré-gelatinizado (Stringhini et al., 2009) e ODS, na dieta de frangos de corte (Vieira et al., 2002). Os resultados encontrados no presente trabalho, todavia, não estão de acordo com os trabalhos realizados por Macari \& Maiorka (2000), Iji et al. (2001) e Waldroup et al. (2003), nos quais se verificaram efeitos positivos sobre o rendimento de carcaça, com a utilização de MOS em dietas para frangos de corte.

Uma das explicações para os resultados obtidos no presente trabalho pode ser a utilização de teores de proteína considerados baixos, nas fases pré-inicial, inicial, de crescimento e final, bem como de teores do aminoácido essencial - lisina - e de níveis de energia

Tabela 5. Média \pm erro-padrão das variáveis ligadas ao desempenho das aves, em diferentes tratamentos de inclusão de núcleo energético-proteico (NEP) nas dietas ${ }^{(1)}$.

\begin{tabular}{|c|c|c|c|c|c|}
\hline $\begin{array}{l}\text { Idade das } \\
\text { aves (dias) }\end{array}$ & $\mathrm{T} 1$ & $\mathrm{~T} 2$ & $\mathrm{~T} 3$ & $\mathrm{~T} 4$ & $\mathrm{P}$ \\
\hline \multicolumn{6}{|c|}{ Peso corporal (kg) } \\
\hline 1 & $0,046 \pm 0,001$ & $0,046 \pm 0,001$ & $0,046 \pm 0,001$ & $0,046 \pm 0,001$ & ns \\
\hline 7 & $0,148 \pm 0,003$ & $0,148 \pm 0,003$ & $0,150 \pm 0,003$ & $0,151 \pm 0,003$ & ns \\
\hline 21 & $0,789 \pm 0,005$ & $0,779 \pm 0,010$ & $0,789 \pm 0,012$ & $0,788 \pm 0,011$ & ns \\
\hline 35 & $1,891 \pm 0,011$ & $1,895 \pm 0,018$ & $1,894 \pm 0,013$ & $1,886 \pm 0,016$ & ns \\
\hline 42 & $2,552 \pm 0,010$ & $2,545 \pm 0,016$ & $2,553 \pm 0,012$ & $2,560 \pm 0,020$ & ns \\
\hline \multicolumn{6}{|c|}{ Ganho de peso $(\mathrm{kg})$} \\
\hline 7 & $0,101 \pm 0,003$ & $0,101 \pm 0,003$ & $0,103 \pm 0,002$ & $0,104 \pm 0,003$ & ns \\
\hline 21 & $0,743 \pm 0,004$ & $0,733 \pm 0,009$ & $0,742 \pm 0,011$ & $0,741 \pm 0,010$ & ns \\
\hline 35 & $1,845 \pm 0,010$ & $1,849 \pm 0,018$ & $1,848 \pm 0,012$ & $1,840 \pm 0,015$ & ns \\
\hline 42 & $2,506 \pm 0,010$ & $2,499 \pm 0,016$ & $2,507 \pm 0,012$ & $2,514 \pm 0,019$ & ns \\
\hline \multicolumn{6}{|c|}{ Consumo de ração (kg) } \\
\hline 7 & $0,127 \pm 0,002$ & $0,128 \pm 0,002$ & $0,128 \pm 0,002$ & $0,131 \pm 0,002$ & ns \\
\hline 21 & $1,063 \pm 0,010$ & $1,068 \pm 0,009$ & $1,086 \pm 0,009$ & $1,083 \pm 0,013$ & ns \\
\hline 35 & $3,080 \pm 0,015$ & $3,081 \pm 0,014$ & $3,113 \pm 0,022$ & $3,094 \pm 0,018$ & ns \\
\hline 42 & $4,458 \pm 0,022$ & $4,445 \pm 0,016$ & $4,497 \pm 0,023$ & $4,490 \pm 0,030$ & ns \\
\hline \multicolumn{6}{|c|}{ Conversão alimentar } \\
\hline 7 & $1,253 \pm 0,023$ & $1,265 \pm 0,022$ & $1,244 \pm 0,017$ & $1,264 \pm 0,020$ & ns \\
\hline 21 & $1,431 \pm 0,013$ & $1,458 \pm 0,013$ & $1,466 \pm 0,027$ & $1,461 \pm 0,011$ & ns \\
\hline 35 & $1,669 \pm 0,011$ & $1,667 \pm 0,013$ & $1,685 \pm 0,014$ & $1,682 \pm 0,006$ & ns \\
\hline 42 & $1,779 \pm 0,008$ & $1,779 \pm 0,009$ & $1,794 \pm 0,011$ & $1,786 \pm 0,003$ & ns \\
\hline \multicolumn{6}{|c|}{ Mortalidade (\%) } \\
\hline 42 & $3,704 \pm 1,852$ & $2,778 \pm 0,926$ & $3,241 \pm 0,839$ & $3,704 \pm 0,700$ & ns \\
\hline
\end{tabular}


Tabela 6. Média \pm erro-padrão das variáveis ligadas às características de carcaça, em consequência de tratamentos com inclusão de núcleo energético-proteico (NEP) nas dietas das aves ${ }^{(1)}$.

\begin{tabular}{lccccc}
\hline Corte & T1 & T2 & T3 & T4 & P \\
\hline Asas (g) & $191 \pm 2,16$ & $190 \pm 3,11$ & $188 \pm 1,59$ & $191 \pm 2,38$ & 0,7947 \\
Peito (g) & $619 \pm 11,71$ & $625 \pm 10,50$ & $634 \pm 11,58$ & $629 \pm 7,94$ & 0,7170 \\
Dorso (g) & $402 \pm 3,80$ & $403 \pm 3,96$ & $402 \pm 4,20$ & $396 \pm 3,68$ & 0,6808 \\
Coxas (g) & $236 \pm 2,83$ & $235 \pm 2,09$ & $238 \pm 2,33$ & $238 \pm 3,55$ & 0,8733 \\
Sobrecoxas (g) & $353 \pm 4,07$ & $358 \pm 4,40$ & $354 \pm 2,59$ & $353 \pm 5,21$ & 0,8098 \\
Gordura abdominal (g) & $37,88 \pm 2,24$ & $36,38 \pm 2,19$ & $43,25 \pm 3,28$ & $32,88 \pm 2,62$ & 0,0667 \\
Carcaça (g) & $1838 \pm 11,14$ & $1847 \pm 15,66$ & $1860 \pm 10,00$ & $1840 \pm 11,72$ & 0,6240 \\
Rendimento de carcaça (\%) & $74,08 \pm 0,29$ & $74,24 \pm 0,28$ & $74,70 \pm 0,24$ & $73,93 \pm 0,44$ & 0,4149 \\
\hline
\end{tabular}

(1)Teor de inclusão de NEP nas dietas: T1, $0 \%$ em todo o período (42 dias); T2, 7\% até 7 dias de idade e 3,5\% até 21 dias; T3, 14\% até 7 dias e 7\% até 21 dias; T4, $21 \%$ até 7 dias e 10,5\% até 21 dias. P, significância estatística do teste F.

mais elevados do que os normalmente utilizados. Tais resultados indicam que a inclusão desses ingredientes pode ter contribuído apenas para elevar o custo do frango produzido, e que apenas os ingredientes comumente utilizados nas rações - milho, farelo de soja, farinha de carne etc.- já são suficientes para que o frango de corte possa expressar todo o seu potencial genético.

\section{Conclusão}

O núcleo energético-proteico, composto por óleo degomado de soja, milho pré-gelatinizado, soja biprocessada, mananoligossacarídeos e peptídeos, utilizado na dieta de frangos de corte, não altera o desempenho das aves e não interfere nas variáveis de características de carcaça, nos primeiros 21 dias de idade dos animais

\section{Agradecimentos}

À Embrapa Suínos e Aves, pelo apoio à execução do estudo.

\section{Referências}

ADIBI, S.A.; MORSE, E.L. The number of glycine residues which limit intact absorption of glycine oligopeptides in human jejunum. The Journal of Clinical Investigation, v.60, p.1008-1016, 1977.

BRITO, A.B. Avaliação nutricional do gérmen integral de milho para aves e seus efeitos no desempenho de frangos de corte. 2005. 97p. Dissertação (Mestrado) - Universidade Federal de Goiás, Goiânia.

DUARTE, F.D.; LARA, L.J.C.; BAIÃO, N.C.; CANÇADO, S.V.; TEIXEIRA, J.L. Efeito da inclusão de diferentes fontes lipídicas em dietas para frangos de corte sobre o desempenho, rendimento e composição da carcaça. Arquivo Brasileiro de Medicina Veterinária e Zootecnia, v.62, p.439-444, 2010.

FARIA, D.E. Avaliação nutricional de soja integral tostada e extrusada para poedeiras comerciais. 1994. 103p. Dissertação (Mestrado) - Universidade Estadual Paulista, Jaboticabal.

FERNANDEZ, J.; CRESPO, N. New advances in the application of probiotics. International Pig Topics, v.18, p.11-13, 2003.

FREITAS, E.R.; SAKOMURA, N.K.; NEME, R.; BARBOSA, N.A.A. Avaliação do milho processado a calor em dietas pré-iniciais sobre o desempenho de frangos de corte. In: REUNIÃO ANUAL DA SOCIEDADE BRASILEIRA DE ZOOTECNIA, 40., 2003, Santa Maria. Anais. Santa Maria: Sociedade Brasileira de Zootecnia, 2003. CD ROM.

FREITAS, E.R.; SAKOMURA, N.K.; NEME, R.; SANTOS, A.L. dos. Valor energético do óleo ácido de soja para aves. Pesquisa Agropecuária Brasileira, v.40, p.241-246, 2005.

HOFACRE, C.L.; BEACORN, T.; COLLET, S.; MATHIS, G. Using competitive exclusion, mannan-oligosaccharide and other intestinal products to control necrotic enteritis. Journal of Applied Poultry Research, v.12, p.60-64, 2003.

HONGTRAKUL, K.; GOODBAND, R.D.; BEHNKE, K.C.; NELSSEN, J.L.; TOKACH, M.D.; BERGSTROM, J.R.; NESSMITH JUNIOR, W.B.; KIM, I.H. The effects of extrusion processing of carbohydrate sources on weanling pig performance. Journal of Animal Science, v.76, p.3034-3042, 1998.

IJI, P.A.; SAKI, A.A.; TIVEY, D.R. Intestinal structure and function of broiler chickens on diets supplemented with a mannan-oligosaccharide. Journal of the Science of Food and Agriculture, v.81, p.1186-1192, 2001.

LARA, L.J.C.; BAIÃO N.C.; AGUILAR, C.A.L.; CANÇADO, S.V.; FIUZA, M.A.; RIBEIRO, B.R.C. Efeito de fontes lipídicas sobre o desempenho de frangos de corte. Arquivo Brasileiro de Medicina Veterinária e Zootecnia, v.57, p.792-798, 2005.

MACARI, M.; MAIORKA, A. Função gastrintestinal e seu impacto no rendimento avícola. In: CONFERÊNCIA APINCO DE CIÊNCIA E TECNOLOGIA AVÍCOLAS, 2., 2000, Campinas. Anais. Campinas: Facta, 2000. p.161-174.

OLIVEIRA, M.C. de; CANCHERINI, L.C.; MARQUES, R.H.; GRAVENA, R.A.; MORAES, V.M.B. de. Mananoligossacarídeos 
e complexo enzimático em dietas para frangos de corte. Revista Brasileira de Zootecnia, v.38, p.879-886, 2009.

PERILLA, N.S.; CRUZ, M.P.; BELALCÁZAR, A.; DIAZ, G.J. de. Effect of temperature of wet extrusion on the nutritional value of full-fat soyabeans for broiler chickens. British Poultry Science, v.38, p.412-416, 1997.

ROSTAGNO, H.S.; ALBINO, L.F.T.; DONZELE, J.L.; GOMES, P.C.; OLIVEIRA, R.F. de; LOPES, D.C.; FERREIRA, A.S; BARRETO, S.L. de T. Tabelas brasileiras para aves e suínos: composição de alimentos e exigências nutricionais. 2.ed. Viçosa: UFV, 2005. 186p.

ROSTAGNO, H.S.; ALBINO, L.F.T.; TOLEDO, R.S.; CARVALHO, D.C.O.; OLIVEIRA, J.E.; DIONIZIO, M.A. Avaliação de prebióticos à base de mananoligossacarídeos em rações de frangos de corte contendo milhos de diferente qualidade nutricional. Revista Brasileira de Ciência Avícola, v.5, p.52, 2003. Suplemento.

SAKOMURA, N.K.; DEL BIANCHI, M.; PIZAURO JUNIOR, J.M.; CAFÉ, M.B.; FREITAS, E.R. Efeito da idade dos frangos de corte sobre a atividade enzimática e digestibilidade dos nutrientes do farelo de soja e da soja integral. Revista Brasileira de Zootecnia, v.33, p.924-935, 2004.

SANTIN, E.; MAIORKA, A.; SILVA, A.V.F.; GRECCO, M.; SANCHEZ, J.C.; MACARI, M. Efeito de diferentes níveis de parede celular de Saccharomyces cerevisiae no desempenho e mucosa intestinal de frangos. Revista Brasileira de Ciência Avícola, v.2, p.37, 2000. Suplemento.
SANTOS, D.A. Utilização do milho pré-gelatinizado na alimentação de leitões (sete a 45 dias) e pintos de corte (um a 21 dias). 2006. 58p. Dissertação (Mestrado) - Universidade Federal de Goiás, Goiânia.

STRINGHINI, J.H.; SANTOS, D.A.; BRITO, A.B. de; NUNES, R. da C.; RUFINO, L.M.; SANTOS, B.M. dos. Desempenho de pintos de corte alimentados com rações contendo milho pré-gelatinizado. Revista Brasileira de Zootecnia, v.38, p.1738-1744, 2009.

SWICK, R.A. Role of growth promotants in poultry and swine feed. 1996. Disponível em: <www.asasea.com/download_doc. php?file=AN04-swick.pdf $>$. Acesso em: 09 set. 2009.

VIEIRA, S.L.; RIBEIRO, A.M.L.; KESSLER, A.M.; FERNANDES, L.M.; EBERT, A.R.; EICHNER, G. Utilização da energia de dietas para frangos de corte formuladas com óleo ácido de soja. Revista Brasileira de Ciência Avícola, v.4, p.127-139, 2002.

WALDROUP, P.W.; OVIEDO-RONDON, E.O.; FRITTS, C.A. Comparison of Bio-Mos antiobiotic feeding programs in broiler diets containing copper sulfate. International Journal of Poultry Science, v.2, p.28-31, 2003.

XAVIER, L.H. Modelos univariado e multivariado para análise de medidas repetidas e verificação da acurácia do modelo univariado por meio de simulação. 2000. 91p. Dissertação (Mestrado) - Escola Superior de Agricultura Luiz de Queiroz, Piracicaba.

$\overline{\text { Recebido em } 22 \text { de abril de } 2010 \text { e aprovado em } 9 \text { de agosto de } 2010}$ 